\title{
ROBOTIC PROCESS AUTOMATION - A DRIVER OF DIGITAL TRANSFORMATION?
} pages: $21-31$

\author{
JULIA SIDERSKA
}

\begin{abstract}
A B S T R A C T
The paper introduces Robotic Process Automation (RPA), which is an emerging and cutting-edge conception of business processes automation, based on the notion of software robots or artificial intelligence workers. The paper is conceptual as it discusses the fundamentals behind this idea, synthesises the knowledge of technology, and presents it in a new context. It is based on the author's considerations and the literature review, which contributes to the insight into the basic understanding of RPA technology as well as systematises and clarifies RPA definitions, identifies market trends, formulates a set of predictions for further development of this technology, and highlights directions for future inquiry. Additionally, logical arguments are proposed for considering RPA as a technology that enables and advances digital transformation. Moreover, criteria are indicated for business processes suitable for RPA. Nowadays, the robotisation of business processes as innovative technology is more often practically implemented than it is investigated by research. Published papers outline real examples of implemented cases of RPA technology in organisations that mainly represent service industries. These case studies allow identifying possible advantages and risks derived from RPA implementation. Recent studies also report benefits of the RPA application in terms of productivity, costs, service quality, and error reduction. Some authors propose the criteria for selecting processes suitable for automation and robotisation. This paper constitutes a foundation for new research aimed at filling knowledge gaps in this area. Responding to the call by van der Aalst, academic discourse on RPA must be initiated.
\end{abstract}

KEY WORDS

Robotic Process Automation, RPA, digital transformation, software robots, digital technologies, artificial intelligence

10.2478/emj-2020-0009
Corresponding author:

Julia Siderska

Bialystok University of Technology, Poland ORCID 0000-0001-5717-8043 e-mail: j.siderska@pb.edu.pl

\section{INTRODUCTION}

With digital technologies shaping competition in many industries, predicting the future of potentially disruptive technologies becomes an essential task of business leaders concerned with the survival and suc- cess of their organisations (Krotov, 2019). Several years have seen the rapid growth of the importance of digital technologies in achieving business goals of organisations. The use of advanced digital technologies transforms business models of organisations,

Citation: Siderska, J. (2020). Robotic Process Automation - a driver of digital transformation? Engineering Management in Production and Services, 12(2), 21-31. doi: 10.2478/emj-2020-0009 
their products, processes and organisational structures. Such changes are called digital transformation, and they revolutionise both individual enterprises as well as whole industries.

Until now, the concept of digital transformation was primarily associated with production processes as physical robots were supporting humans in manufacturing tasks. At the beginning of the digital transformation era, all attempts were mainly directed towards providing the highest quality of customer service. Currently, increasingly more attention is devoted to the digitisation of operational and business processes, and the concept of digitisation itself also covers service enterprises, including primarily such industries as finance, banking, insurance, marketing, accounting, public administration, logistics, etc.

Rapidly changing market demands, and the dynamic development of information technologies significantly contribute to the evolution of modern management concepts using IT tools. While the robotisation of production processes (the manufacturing sphere of an organisation) emerged in the $1950 \mathrm{~s}$, the robotisation of business processes (the sphere of management) is still at the beginning of the expansion and seems to have a potential for development in companies. In this context and the light of the available literature on the subject, such robotisation should be widely understood as the automation of business processes through the extensive use of "robots", i.e. software that replaces people in certain activities. RPA is used to automate data-intensive and repetitive tasks for improved process efficiency. Robotic Process Automation literally may suggest physical robots occupying office space, performing human tasks, and being involved in business processes. However, RPA is essentially a software-based solution, and the software "robot" is expected to perform activities previously undertaken by people (Das, 2019). Detailed considerations specifying the meaning of this concept are presented in the next chapter.

The value of the RPA market has been increasing for several years, and the analytics anticipate further development of this sector. To illustrate this intensifying adoption of RPA solutions in companies, Forrester predicted that by 2021 , more than four million robots would be implemented for office tasks. Moreover, according to these forecasts, the RPA market would reach USD 2.9 billion by 2021, from USD 250 million in 2016 (Le Clair, 2018). Gartner considered RPA as "the fastest-growing segment of the global enterprise software market" and anticipated that the global market for RPA services would hit an estimated EUR 7 billion in 2020 (Gartner, 2017). It is worth emphasising that it is currently the most rapidly developing segment of the global software market. According to Information Services Group (2018), $54 \%$ of European companies plan to automate at least ten processes via RPA within 2020. The RPA industry is growing rapidly, driven by digital business demands as organisations look for "straight-through" processing.

Aiming to meet the set goals, the paper is structured as follows. The introduction is followed by a brief background on RPA and the literature review, which systematises RPA definitions and indicates the main possibilities that open up with the application of such solutions in service companies. The third part of the paper identifies the main characteristics and advantages for enterprises considering the implementation of automated software robots. In addition, the author offers several arguments for considering RPA as an emerging and cutting-edge technology that enables digital transformation. Next, criteria are formulated for processes that are suitable for RPA. In the third chapter, the author indicates the proposals of integrating RPA with other disruptive technologies. The proposals are followed by future-oriented predictions for further development of RPA tools. The last part of the paper offers conclusions and highlights directions for prospective inquiry.

\section{LITERATURE REVIEW}

Insufficient literature is available on Robotic Process Automation as a niche and nascent field. Although RPA is an emerging and promising technology, scientific research is almost absent. The academic research mainly lacks a theoretical and synoptic analysis of such an approach. Some authors have documented its features and benefits in whitepapers and case studies. However, there is a need for a comprehensive assessment of this concept, indicating roadmaps for effective deployment towards organisational value creation (Das, 2019).

The literature analysis was conducted by the author aiming to provide an insight into the fundamental understanding of RPA and to systematise RPA definitions offered in different scientific papers. Researchers represent three main approaches to understanding and defining the essence of this concept. The literature considers it as emerging technology, a software tool, or a process automation 
approach. However, all proposed definitions emphasise the reduction of the burden of repetitive, simple tasks and their automation as the main aim of those tools. They enable employees to be involved in more complicated tasks that require creativity and which can bring more value to an organisation. The technology is mostly driven by simple rules and business logic. It interacts with multiple information systems through existing graphic user interfaces. Its functionalities comprise the automation of repeatable and rule-based activities (Greyer-Klingeberg et al., 2018). Fig. 1 presents the key areas for the application of automated software robots.

Santiago and Rodriguez (2019) determined the concept of RPA as an "automation technology based on software tools that could imitate human behaviour for repetitive and non-value added tasks, such as tipping, copying, pasting, extracting, merging and moving data from one system to another". According to Gartner (2017), "RPA tools perform [if, then, else] statements on structured data, typically using a combination of user interface interactions, or by connect- ing to APIs to drive client servers, mainframes or HTML code. An RPA tool operates by mapping a process in the RPA tool language for the software robot to follow, with runtime allocated to execute the script by a control dashboard". Based on Slaby (2012), RPA is the technological imitation of a human worker aimed at fast and cost-efficient automation of structured tasks. Some authors also pointed to several RPA disadvantages that companies must consider when adopting RPA to automate processes. This technology is only suited for rule-based processes because it is executed by a robot without cognitive skills. Moreover, processes containing many exceptions should be handled by workers (Santos et al., 2019). It should also be emphasised that such processes must be firstly identified, standardised and optimised. According to studies by the IEEE Advisory Group (IEEE SA, 2017), RPA technology is "preconfigured software instance that uses business rules and predefined activity choreography to complete the autonomous execution of a combination of processes, activities, transactions and tasks in one or more unrelated software systems

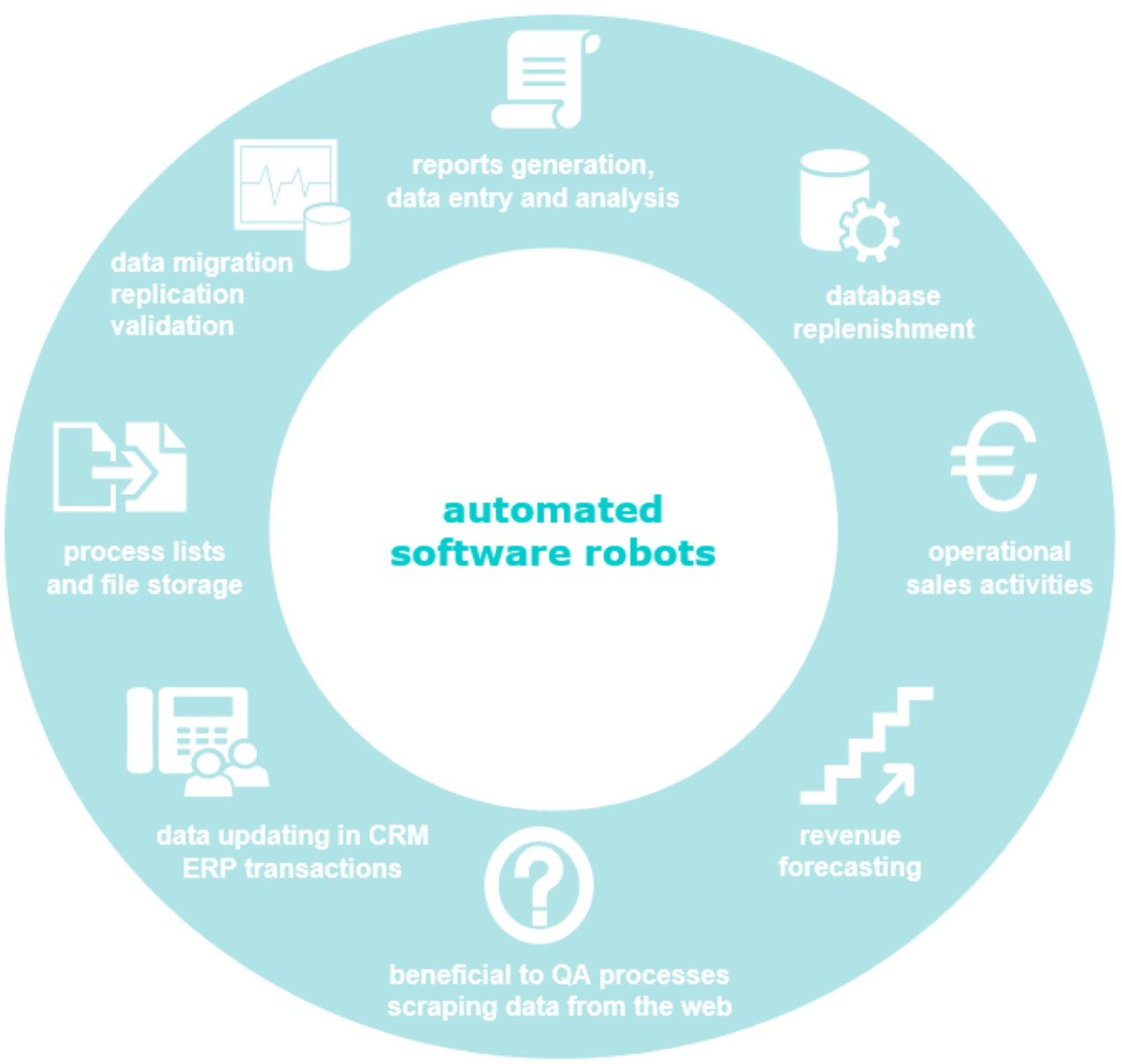

Fig. 1. Leading applications of automated software robots. 
to deliver a result or service with human exception management".

In the literature on the subject, the RPA conception is also identified as a process automation approach. According to Quinn and Strauss (2018), RPA is "a fast-emerging process automation approach that uses software robots to replicate human tasks. After recording a process workflow, a virtual bot mimics the actions performed by humans in the application's graphical user interface and automate their execution". A similar definition was proposed by Lacity and Willcocks, stating that "RPA can automate rules-based processes that involve routine tasks, structured data and deterministic outcomes". Most applications of RPA were created for automating tasks of service business processes (Fig. 1). RPA is commonly perceived "as a productivity and effectiveness tool as it reduces errors, increases security and helps lessen human mistake" (Dialani, 2019).

Automated software robots are increasingly adopted in many areas, such as human resources (Hallikainen et al., 2018), IT (Khramov, 2018), finance (Lacity et al., 2017), insurance (Lacity \& Willcocks, 2017), telecommunication (Lacity et al., 2015), education (Herbert, 2016), banking (Willcocks et al., 2017), legal services (Holder et al., 2016), realestate management and logistics (Jurczuk, 2019).

According to some authors, RPA should be considered from two perspectives, namely, the future of an organisation and changes in the labour market. The first approach should be understood as the occurrence of natural processes resulting from technological development, the rapid pace of knowledge growth, and their impact on the economic environment of an organisation. The second approach may be defined as a reconfiguration of the current and the formation of new, previously unknown workplaces in the labour market (Śliż, 2019).

\section{RPA CHARACTERISTICS OF AND ITS INFLUENCE ON DIGITAL TRANS- FORMATION}

Robotic Process Automation should be considered as one of the digital transformation technologies supporting companies in robotising repeatable and routine tasks. Just like other advanced solutions, RPA enables higher efficiency. By programming autonomous software robots to replicate basic administrative processes, it merges software, artificial intelligence, and machine learning capabilities to automate manual tasks that are normally operated by humans (Kudlak, 2019).

Software robots developed with the use of RPA tool allow solving plenty of business problems. Next, the main characteristics and advantages are listed for an enterprise after implementing such solutions (Sobczak, 2019; Anagoste, 2017; the author):

- the ability for employees supported by robots to handle more processes, work more efficiently and commit fewer errors in analysing data;

- the increased repeatability, reproducibility, and quality of most office processes;

- the robotisation of processes that relieves employees from the most routine, repetitive tasks, entrusting them with more demanding duties; the raised standardisation of repetitive tasks to a higher level;

- more time for employees to engage in creative work and problem-solving; business processes made up to ten times faster;

- quick results brought by RPA, possible to be implemented in organisations with a technological debt;

- checks and takes performed in consideration validation points according to a predefined set of rules;

- flawless work with multiple systems, interconnecting many computer applications and systems (e.g. PDF, MS Excel, ERP system, PowerPoint etc.);

- a case provided for the introduction of analytics;

- a possibility to personalise a solution for an individual user, extract specific information from e-mails and respond with security procedures and data confidentiality;

- the reliability of software robots as they constantly adhere to the predefined workflow, which increases process reliability and compliance;

- the robotisation of business processes can be implemented in many industries (nowadays, it is mainly used in accounting and finance, banking, insurance, telecommunications and logistics);

- reduced operational costs.

The fundamental issue for the company should be the appropriate identification of processes to be automated using RPA technology. A proper selection of processes for robotisation is critical as it differs at the Proof-of-Concept stage and during the implementation in an organisation. The analyses allowed to indicate a set of ideal processes, considering their frequency and complexity. The study by Capgemini 
Consulting assumed that highly frequent processes with low complexity were typically automated using some of the traditional business process automation methods, while processes that were more complex and more frequent were ideal for RPA automation. Also, processes with low frequency and high complexity should not be automated using RPA (Fig. 2).

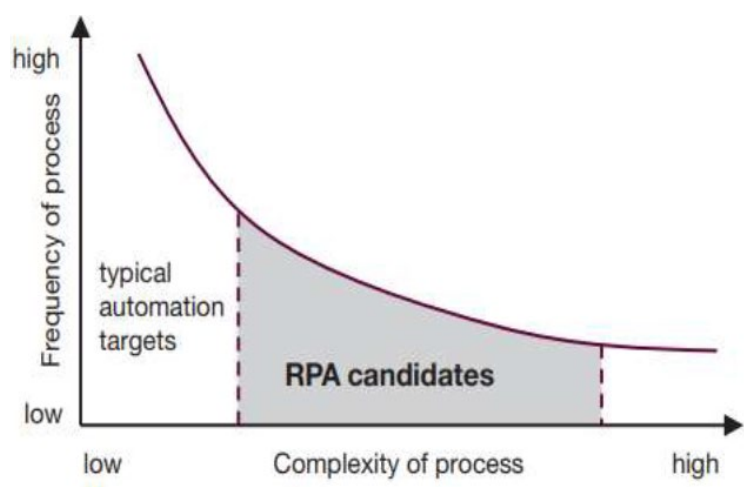

Fig. 2. RPA candidates by frequency and complexity of a process Source: (Jovanovic et al., 2018).

According to Fung (2014), the typical criteria for processes suitable for RPA are:

- low cognitive requirements (it is hardly possible for complex processes with many complicated tasks to be handled by RPA);

- no requirement for the access to multiple systems as RPA is applied on top of existing applications;

- relatively frequently performed processes and tasks are good candidates for RPA implementation;

- processes with a high probability of human error and limited exceptions should be selected first for RPA.

Over the last few years, digital transformation was mostly influenced by such technologies as cloud, edge computing, IoT, and AR (Gudanowska, 2017; Siderska \& Jadaan, 2018; Ślusarczyk, 2018; Ejdys et al., 2019; Krykavskyy, 2019; Nosalska \& Mazurek, 2019; Gudanowska \& Kononiuk, 2020; Halicka, 2020). However, analytics emphasise that up to 2020 , a set of such technologies will be supplemented with others that will significantly affect the digital revolution, namely, 5G, AI, advanced analytics, Machine Learning, blockchain (Hofbauer \& Sangl, 2019), conversational AI, XaaS, connected vehicles, autonomous drones, and smart cities (Szpilko, 2020; Forbes, 2019; Winkowska et al., 2019).

In the author's opinion, RPA should also be considered an emerging and cutting-edge technology that enables digital transformation. The fourth industrial revolution is powered by the rise of such digital technologies as rapidly transforming processes and human-technology relationships. The technology substitutes manual labour, no longer playing a supporting role. Taking up the challenges of the digital revolution to digitise operational processes and automate some routine tasks, a growing number of companies is implementing disruptive technologies and modern IT tools, including principally Robotic Process Automation (RPA). Such solutions are userconfigurable, do not require code writing and use non-invasive techniques (operating on HTML pages, "screen scraping" or scripts that enable work in many different environments, e.g. ERP, CRM, workflow, or email programs). As a result, RPA technology should be considered one of the enablers of Industry 4.0 and digital transformation, as it supports business processes transformation, product development, and new emerging business models. It also allows to achieve better operational efficiency and reduce significantly operational costs.

In the Age of Digital Transformation, artificial intelligence and machine learning enable robots to learn new skills as well as extend the scope of their work beyond rules-based-action to conclusions and decision-making tasks. To help humans, software robots should not only undertake the basic work but also have to be able to act intelligently (Kirkwood, 2019). Robotic Process Automation technologies are becoming compulsory as a part of business operations in an organisation. It should be noted that RPA technologies will undertake repetitive tasks and even get involved in risky processes of human life (Madakan et al., 2019). Due to increased versatility and disruptive potential to transform business processes, intelligent automation will be the next milestone for worth-while investments. The joint use of RPA and complementary technologies (artificial intelligence, business process management, OCR, process orchestration, machine learning, or natural language processing) enables the automation of increasingly more complex processes.

\section{FUTURE RPA OPPORTUNITIES}

RPA supported by modern technologies will become more comprehensive and all-embracing. Together with artificial intelligence, robots will come up with different solutions to further ease the workflow of organisations. Bots, combined with intelligent technologies, accelerate the rate of the learning process. Software, which is integrated with such tech- 
nologies as Machine Learning, artificial (cognitive) intelligence, Natural Language Processing and data analytics, can analyse and process data available in real-time. Furthermore, it can accurately predict the time left to complete a task or a milestone while still executing the process or even beforehand. The industries will be assisted by RPA to streamline business processes all the time and optimise operational efficiency.

Table 1 presents the proposals found in the literature regarding the integration of RPA with other cutting-edge technologies and areas.

RPA is often discussed and described in the literature as a gateway technology to artificial intelligence. Dialani (2019) found that Robotic Process Automation as "the subset of AI that empowers IT groups to configure software 'robots' to capture data and perform routine tasks, is picking up traction as an alluring spot to start with outcomes centred AI implementation. RPA is getting one of the most exciting opportunities in the AI space and will keep on sparkling in 2020". Future trends suggest that there will be a collaboration between bots and humans in many areas (Seibt \& Vestergaard, 2018). As a result, more jobs will be created by enhancing the nature of jobs, and there will be a need for RPA and process experts to augment user interfaces and solve business problems.

Tab. 1. Integration of RPA and other technologies

\begin{tabular}{|c|c|}
\hline TECHNOLOGY & REFERENCES \\
\hline $\begin{array}{l}\text { Integration with machine } \\
\text { learning/ artificial intel- } \\
\text { ligence/ cognitive intel- } \\
\text { ligence/ Natural } \\
\text { Language Processing }\end{array}$ & $\begin{array}{ll}\text { - } & \text { Anagnoste (2017), } \\
\text { - } & \text { Anagnoste (2018), } \\
\text { - } & \text { val der Aalst et al. (2018), } \\
\text { - } & \text { Sobczak (2019), } \\
\text { - } & \text { Madakam et al. (2019), } \\
\text { - } & \text { Dialani (2019), } \\
\text { - } & \text { Kudlak (2019) }\end{array}$ \\
\hline $\begin{array}{l}\text { Integration with big data/ } \\
\text { analytics/data analysis }\end{array}$ & $\begin{array}{ll}\text { - } & \text { Anagnoste (2017), } \\
\text { - } & \text { Tian (2018), } \\
\text { - } & \text { Ivancic et al. (2019) }\end{array}$ \\
\hline $\begin{array}{l}\text { Integration with process } \\
\text { mining }\end{array}$ & $\begin{array}{l}\text { - } \quad \text { val der Aalst et al. (2018), } \\
\text { - } \quad \text { Tornbohm and Dunie (2017), } \\
\text { - } \quad \text { Ivancic et al. (2019), } \\
\text { Geyer-Klingeberg et al. } \\
\text { (2018) }\end{array}$ \\
\hline $\begin{array}{l}\text { Integration with BPM/ } \\
\text { BPMS }\end{array}$ & $\begin{array}{l}\text { - } \quad \text { Mendling et al. (2018), } \\
\text { - } \quad \text { Ivas (2019), } \\
\text { - } \quad \text { Sancic et al. (2019), } \\
\text { - Śliż (2019), } \\
\text { - Jovanović et al. (2018) }\end{array}$ \\
\hline
\end{tabular}

The constant advancement of RPA and AI is hard to keep up with; however, following these global trends can provide companies with competitive advantages and domination in the market (Kot \& Leszczyński, 2019). It is worth-while stressing that the comprehensive potential contributed by RPA to organisations across all industries should encourage their development and adaptation of a digital transformation strategy.

According to Forrester, most organisations have already automated at least $20 \%$ of service desk-tasks, and more than a million knowledge-worker jobs will be replaced by software robotics, RPA, virtual agents and chatbots and ML-based decision management (Forrester, 2019). However, this does not mean that posts will be freed, and workers will lose their jobs. Jurczuk claims that the current perception of the role of human resources must be reformulated and new roles in business processes must be indicated. The use of opportunities offered by new technologies should be the role of entrepreneurs and the process management approach (Jurczuk, 2019). The nature of performed tasks will change and, therefore, completely different employee competencies will be prioritised, including advanced digital competences. As the rate of RPA maturity and technology advancement will continue to accelerate in the near future, organisations will need to standardise and scale their automation. Moreover, they will have to address business challenges with a hybrid human/software workforce, using software robots to automate daily processes and freeing humans for more creative, strategic tasks.

Future-oriented predictions for further development of RPA tools were considered by Kirkwood, chief of UiPath - the global leader in the development of RPA platforms and the first vendor of scale to bring together process mining and Robotic Process Automation (Kirkwood, 2019):

- The global economic downturn will encourage the adoption of automation. As businesses face the realities of working in an economic downturn, they should adapt their business models with automation, which will enable them to scale up robots rather than scale down human employees;

- RPA is going to claim its place as a central platform for other enterprise automation tools. This is the front end of an even longerterm trend, as RPA becomes more accessible and extensible;

- More organisations will combine and reuse robots. In 2020, organisations will learn how to 
better standardise robots and apply them across use-cases and departments, and eventually across companies and industries;

- Students entering the workforce will drive automation deployment. So far, human employees have been stuck having to connect and integrate increasingly outdated technology systems via repetitive, manual work. As new employees get more efficient and effective, the now vivid benefits of RPA will outweigh any remaining hesitancy, compelling organisation to change;

- The abilities of machine intelligence are continuing to grow. Tasks that we once thought uniquely human are quickly becoming doable by software. The growth of AI will remain exponential, RPA will become a topic discussed on the world stage;

- The impact of automation is proving to be societal in scope. In 2020, extra-governmental organisations such as the United Nations and the World Economic Forum will discuss RPA in the context of jobs, wages, and global economics. Individual countries will also become increasingly interested in what effect automation will have on their societies.

Robotic Process Automation should be considered a bridge between manual processes and full automation. As one of the core elements of Industry 4.0 , it is the next step in the transformation attempts of companies. Although RPA software can be implemented in all industries, the biggest adopters are banks, insurance companies, telecommunication and utility companies. These organisations have traditionally had many legacy systems; therefore, they choose RPA solutions to ensure integration functionality. By using this technology, organisations can quickly accelerate their digital transformation initiatives while unlocking the value associated with past technology investments.

Nowadays, software robots can be more efficiently standardised, and this warrants their application across a wider range of use cases, departments, whole companies, and even industry sectors. By combining bots into reusable and repeatable elements, both their applicability and their power are enlarged to a considerable extent. Because of its increased versatility and disruptive potential to transform business processes, intelligent automation will be the next milestone for worth-while investments. The automation of increasingly more complex processes is enabled by the joint use of RPA and comple- mentary technologies, such as artificial intelligence, business process management, optical character recognition, process orchestration, machine learning, and natural language processing.

Gartner considered cognitive automation a strategic trend and labelled it "hyperautomation". The expected benefits include increased capacity of robots to master unstructured data, to engage in intricate decision-making processes that consider a wider range of variables, and to learn from experience. As a consequence, the performance of a wide spectrum of business processes will be significantly upgraded. It is also possible to imply that RPA will be combined with Artificial Intelligence (RPAAI). Such an approach constitutes the concept of cognitive automation, combining AI with the automation of business processes. Sobczak believed that the use of the term "Augmented Intelligence" (AUI) was more justified, in the sense of enhanced or augmented intelligence. From the technological point of view, artificial intelligence and augmented intelligence use the same tools (e.g., Machine Learning/Deep Learning) but the overtone of these concepts is completely different as AI implies human replacement while AUI enhances human potential through appropriate, intelligent technologies (Sobczak, 2019).

In the author's opinion, the future-oriented business processes automation will definitely depend on Smart Process Automation, implementing AI, enabling workforce orchestration, robotic and cognitive automation. Therefore, the conducted literature review and RPA market analyses allow considering this technology not only as a trend but mainly as an opportunity for enterprises to achieve competitiveness and shape proper organisational culture. Relieved of tedious and repetitive tasks, which usually waste their potential, employees can freely use their creativity.

Following the introduction of software robots to enterprises, an interdisciplinary area of research called robonomics emerged, which is mainly concerned with advanced technologies (using AI) of automation and robotisation from the perspective of their economic impact on organisations (Ivanov, 2017). Recently, the RPA conception was extended towards its conjunction with artificial intelligence, cognitive computing, process mining and data analytics. The introduction of advanced digital technologies allows RPA to be reallocated from performing repetitive and error-prone routines in business processes towards more complex knowledge-intensive and value-adding tasks (Ivancic et al., 2019). 


\section{CONCLUSIONS}

Robotisation of processes raises emotions due to many different reasons. Some authors claim that robotics is a progressive social revolution, perhaps even the same as the Information Age or the Industrial Age (Forbes, 2017). The main objectives for business process automation are increasing the efficiency and revenue as well as reducing the overhead. Digital transformation of the 21st century would be impossible without robots and automation. Therefore, it seems that RPA as a concept and class of information systems will be gaining importance in the modern business environment, in which information is processed on an unprecedented scale.

RPA is more often practically implemented than investigated by research. Responding to the call by van der Aalst (van der Aalst et al., 2018), the paper also aims to initiate the academic discourse about RPA. This paper is conceptual (Gilson \& Goldberg, 2015) as it discusses the fundamentals of the concept, synthesises knowledge of technology, and presents it in a new context to constitute a foundation for new research aimed at filling knowledge gaps in this area. The conducted literature analysis identified a theoretical and empirical research gap. One of the possible directions for future research is the investigation of direct and indirect effects of RPA on organisational performance. It is essential to discuss differences, similarities, and complementarities between RPA and similar technologies and approaches to business process management (BPM/BPMS). Researchers should seek to determine strategic approaches to RPA solutions that could be chosen to design the implementation process and the ongoing management of software robots in a successful and sustainable way. As with any major decision in an organisation, decision-making in the context of RPA must follow a strategic approach.

RPA is one of the automation tools that need to be integrated with other tools, such as BPMS, and in the near future, with cognitive automation tools (software robots are expected to learn and mimic human behaviour and handle complex use cases). For long-term development, RPA needs to be extended beyond the rigid rule-based methods. Therefore, the combination of RPA with artificial intelligence (mainly including machine learning techniques), big data, and the data mining concept are foreseen to generate and execute refined process models. This is referred to as smart process automation, which is a possible extension of RPA.
Robotisation of business processes on a large scale must be treated as an organisational and technological change, which leads to the emerging hybrid work environment (business application, software robots, processes and procedures and people with specific competences and skills). There is certainly no reason to fear that robots will banish people. On the contrary - employees and machines (software robots) will become one hybrid environment. It should also be emphasised that working in such an environment requires picking up many gauntlets. Until now, managers have focused only on HR management, often without excavating details of the technology. The point is, they will have to supervise teams consisting of both people as well as bots (Sobczak, 2019). Considering a human labour perspective, researchers should also deal with RPA's potential future impacts on employees and their perceptions of software robots, mainly trust in technology (Ejdys, 2018), human-robot interactions and collaboration. In this context, strategic initiatives to deploy RPA should consider employee engagement, the development of skills and competencies, and sourcing of decisions. With changing areas of responsibility, enterprises should rethink employee roles (Vedder \& Guynes, 2016).

Although RPA will not eliminate entire jobs, it is expected to have an effect on some jobs. In 2020, the United Nations and the World Economic Forum are expected to discuss RPA in the context of jobs, wages and global economics. Individual countries will also become increasingly interested in the effects of automation on societies. Analysts are also convinced that "developing a digital transformation strategy that encourages an automation-first mindset will be vital for a company's future survival RPA is just one component of a broader intelligent automation platform that must be combined with other automation technologies". Adopting an "automation first" mindset is the initial step for implementing digital transformation in a company. Such an approach to the problem enables an enterprise to develop, serve customers better and operate more efficiently and effectively. It unburdens employees from mundane, repetitive work, allowing them to focus on problem-solving and value-creation.

One of the most important challenges is identifying processes suitable for RPA automation (Leopold et al., 2018). It is critical to select an appropriate process for automation to avoid increased inefficiency and failure (Gadre et al., 2017). Aiming to determine appropriate processes for automation, it is necessary 
to establish criteria that help to recognise the suitability of a process for RPA. A link with process mining also seems obvious as process identification can be used to learn "by example" to subsequently detect process fragments that are suitable for RPA (van der Aalst et al., 2018). Future research by the author will include the development of a set of key criteria for business processes selection suitable for robotisation with the help of RPA tools (process mining) and the development of a conceptual framework for assessing the readiness of a service enterprise to implement such solutions. Moreover the fundamentals of cognitive automation and human-robot interactions and collaboration will be deepened.

\section{LITERATURE}

Anagoste, S. (2017). Robotic Automation Process - The next major revolution in terms of back office operations improvement. Proceedings of the 11th International Conference on Business Excellence, 676-686. doi: 10.1515/picbe-2017-0072

Anagoste, S. (2018). Robotic Automation Process - The operating system for the digital enterprise. Proceedings of the 12th International Conference on Business Excellence, 54-69. doi: 10.2478/picbe-2018-0007

Arindam, D. (2019). Robotic process automation: assessment of the technology for transformation of business processes. International Journal of Business Process Integration and Management, 9(3), 220-230. doi: 10.1504/IJBPIM.2019.100927

Capgemini Consulting. (2016). Robotic Process Automation - Robots conquer business processes in back offices. Retrieved from https://www.capgemini.com/ consulting-de/wpcontent/uploads/sites/32/2017/08/ robotic-processautomation-study.pdf

Dialani, P. (2019). 4 Robotic Process Automation Trends for 2020. Analytics Insight. Retrieved from https:// www.analyticsinsight.net/4-robotic-process-automation-trends-for-2020/

Ejdys, J. (2018). Building technology trust in ICT application at a university. International Journal of Emerging Markets, 13(5), 980-997. doi: 10.1108/IJoEM-07-2017-0234

Ejdys, J., Gudanowska, A., Halicka, K., Kononiuk, A., Magruk, A., Nazarko, J., Nazarko, Ł., Szpilko, D., \& Widelska, U. (2019). Foresight in Higher Education Institutions: Evidence from Poland. Foresight and STI Governance, 13(1), 77-89. doi: 10.17323/25002597.2019.1.77.89

Fung, H. P. (2014). Criteria, use cases and effects of information technology process automation (ITPA). Advances in Robotics and Automation, 3(3), 1-10. doi:10.4172/2168-9695.1000124

Gadre, A., Jessel, B., \& Gulati, K. (2017). Rethinking robotics? Take a step back. Retrieved from www.capco.
com/-/media/CapcoMedia/Capco-Institute/Journal-46/JOURNAL46_full_web.ashx\#page=104

Gardner, Ch., Le Clair, G., Gownder, J. P., Betz, Ch., O’Donnell, G., Lipson, A., \& Lynch, D. (2019). Predictions 2020: Automation Utilize Strike Teams To Fend Off The Automation. Retrieved from https:// www.forbes.com/sites/forrester/2019/11/14/predictions-2020-automation-strike-teams-and-servicesrise-to-fend-off-a-paradox/\#73acde824100

Geyer-Klingeberg, J., Nakladal, J., Baldauf, F., \& Veit, F. (2018). Process Mining and Robotic Process Automation: A Perfect Match. 16th International Conference on Business Process Management 2018, Industry Track Session, Sydney, Australia.

Gilson, L., \& Goldberg, C. (2015). So, What Is a Conceptual Paper? Group \& Organization Management, 40(2), 127-130. doi: 10.1177/1059601115576425

Gudanowska, A. E., \& Kononiuk, A. (Eds). (2020). Uwarunkowania ucyfrowienia procesów produkcji $i$ wzrostu kompetencji cyfrowych społeczeństwa [The conditions for the digitisation of production processes and the growth of digital competence in society]. Białystok, Poland: Oficyna Wydawnicza Politechniki Białostockiej. doi: 10.24427/978-83-66391-23-9.

Gudanowska, A. E. (2017). Transformation towards Industry 4.0-identification of research trends and aspect of necessary competences in the light of selected publications. Research in Logistics \& Production, 7(5), 431441. doi: 10.21008/j.2083-4950.2017.7.5.4

Halicka, K. (2020). Technology Selection Using the TOPSIS Method. Foresight and STI Governance, 14(1), 85-96. doi: 10.17323/2500-2597.2020.1.85.96

Hallikainen, P., Bekkhus, R., \& Pan, S. L. (2018). How Opuscapita used internal RPA capabilities to offer services to clients. MIS Quarterly Executive, 17(1), 41-52.

Herbert, I. P. (2016). How students can combine earning with learning through flexible business process sourcing: a proposition. Loughborough, United Kingdom: Loughborough University.

Hofbauer, G., \& Sangl, A. (2019). Blockchain Technology and Application Possibilities in Digital Transformation of Transaction Processes. Forum Scientiae Oeconomia, 7(4), 25-40, doi: 10.23762/fso_Vol7_ no4_2

Holder, C., Khurana, V., Harrison, F., \& Jacobs, L. (2016). Robotics and law: Key legal and regulatory implications of the robotics age. Computer Law and Security Review, 32(3), 383-402. doi: 10.1016/j. clsr.2016.03.001

IEEE Guide for Terms and Concepts in Intelligent Process Automation (2017). IEEE Std 2755-2017, 1-16.

Ivančić, L., Vugec, D. S., \& Vuksic, V. B. (2019). Robotic Process Automation: Systematic Literature Review. Business Process Management: Blockchain and Central and Eastern Europe Forum, Springer, 280-295.

Ivanov, S. (2017). Robonomics - principles, benefits, challenges, solutions. Yearbook of Varna University of Management, 10, 283-293. 
Jurczuk, A. (2019). Wieloaspektowa identyfikacja i typologia źródel niespójności procesów biznesowych [Multifaceted identification and typology sources of business process inconsistencies sources]. Białystok, Poland: Oficyna Wydawnicza Politechniki Białostockiej. doi: 10.24427/978-83-65596-93-2

Khramov, D. (2018). Robotic and machine learning: how to help support to process customer tickets more effectively. Bachelor's thesis. Helsinki, Finland: Metropolia University of Applied Sciences.

Kirkwood, G. (2019). Seven predictions for robotic process automation (RPA) in 2020. Retrieved from https://industryeurope.com/sectors/automationandrobotics/7-predictions-for-robotic-process-automation-rpa-in-2020/

Kobayashi, T., Arai, K., Imai, T., \& Sato, H. (2019). Communication Robot for Elderly based on Robotic Process Automation. IEEE 43rd Annual Computer Software and Applications Conference (COMPSAC), Milwaukee, United States, 251-256. doi: 10.1109/COMPSAC.2019.10215

Krotov, V. (2019). Predicting the Future of Disruptive Technologies: The Method of Alternative Histories. Harvard Business Publishing.

Kot, M., \& Leszczyński, G. (2019). Development of intelligent agents through collaborative innovation. Engineering Management in Production and Services, 11(3), 29-37. doi: 10.2478/emj-2019-0018

Kripalani, N. (2019). Trends 2020: Five Robotic Process Automation (RPA) predictions for the coming year. Dataquest India. Retrieved from https://www.dqindia.com/trends-2020-five-robotic-process-automation-rpa-predictions-coming-year/

Krykavskyy, Y., Pokhylchenko, O., \& Hayvanovych, N. (2019). Supply chain development drivers in Industry 4.0 in Ukrainian enterprises. Oeconomia Copernicana, 10(2), 273-290. doi: 10.24136/oc.2019.014

Kudlak, L. (2019). Don't underestimate the power of robotic process automation. Will the Age of Ultron come to our world? Retrieved from: https://medium. com/tech4planet/dont-underestimate-the-power-ofrobotic-process-automation- $8 \mathrm{ffb} 8262 \mathrm{~d} 62 \mathrm{f}$

Lacity, M., Willcocks, L. P., \& Craig, A. (2015). Robotic process automation at Telefonica O2. MIS Quarterly Executive, 15(1), 4.

Lacity, M. Willcocks, L. P., \& Craig, A. (2015). Robotic process automation: mature capabilities in the energy sector. The Outsourcing Unit Working Research Paper Series. London, United Kingdom: The London School of Economics and Political Science.

Lacity, M., Khan, S., \& Carmel, E. (2016). Employing US military families to provide business process outsourcing services: a case study of impact sourcing and reshoring. Communications of the Association for Information Systems, 39, 9. doi: 10.17705/1CAIS.03909

Lacity, M., Willcocks, L. P., \& Craig, A. (2016). Robotizing global financial shared services at royal DSM. The Outsourcing Unit Working Research Paper Series.
Lacity, M., \& Willcocks, L. P. (2016). A new approach for automating services. MIT Sloan Management Review. Retrieved from http://eprints.lse.ac.uk/68135/1/ Willcocks_New\%20approach_2016.pdf

Lacity, M., Willcocks, L. P., \& Craig, A. (2017). Service automation: cognitive virtual agents at SEB bank. Retrieved from http://www.umsl.edu/ lacitym/ LSEOUWP1701.pdf

Le Clair, C. (2018). The Forrester WaveTM: robotic process automation. Forrester.

Leopold, H., van der Aa, H., \& Reijers, H. A. (2018), Identifying candidate tasks for robotic process automation in textual process descriptions. Enterprise, Business-Process and Information Systems Modeling, 318, 67-81. doi: 10.1007/978-3-319-91704-7_5

Madakam, S., Holmukhe, R. M., \& Jaiswal, D. K. (2019). The future digital work force: Robotic Process $\mathrm{Au}$ tomation (RPA). Journal of Information Systems and Technology Management, 16. doi: 10.4301/S18071775201916001

Mendling, J., Decker, G., Hull, R., Reijers, H. A., \& Weber, I. (2018). How do Machine Learning, Robotic Process Automation, and Blockchains Affect the Human Factor in Business Process Management? Communications of the Association for Information Systems, 43(1), 297-320. doi: 10.17705/1CAIS.04319

Nosalska, K., \& Mazurek, G. (2019). Marketing principles for Industry 4.0 - a conceptual framework. Engineering Management in Production and Services, 11(3), 9-20. doi: 10.2478/emj-2019-0016

Quinn, M., \& Strauss, E. (2018). The Routledge Companion to Accounting Information Systems. Abingdon, United Kingdom: Routledge.

Romão, M., Costa, J., \& Costa, C. J. (2019). Robotic Process Automation: A case study in the Banking Industry. 14th Iberian Conference on Information Systems and Technologies (CISTI), Coimbra, Portugal.

Santos, F., Pereira, R., \& Vasconcelos, J. B. (2019). Toward robotic process automation implementation. Business Process Management Journal, 3(1). doi: 10.1108/ BPMJ-12-2018-0380

Seibt, J., \& Vestergaard, C. (2018). Fair Proxy Communication: Using Social Robots to Modify the Mechanisms of Implicit Social Cognition. Research Ideas and Outcomes, 4. doi: 10.3897/rio.4.e31827

Sibalija, T., \& Jovanović, S., \& Đurić, J. (2018). Robotic Process Automation: Overview and opportunities. International Journal Advanced Quality, 46(3-4), 33-39.

Siderska, J., \& Jadaan, K. S. (2018). Cloud manufacturing: a service-oriented manufacturing paradigm. A review paper. Engineering Management in Production and Services, 10(1), 22-31. doi: 10.1515/emj-2018-0002

Sobczak, A. (2018). Robotyzacja procesów biznesowych stan obecny i perspektywy rozwoju. Przegląd Organizacji, 10, 52-61. doi: 10.33141/po.2018.10.07

Szpilko, D. (2020). Foresight as a Tool for the Planning and Implementation of Visions for Smart City Development. Energies, 13(7), 1782. doi:10.3390/en13071782 
Śliż, P. (2019). Robotization of Business Processes and the Future of the Labor Market in Poland - Preliminary Research. Organization and Management, 2(185), 67-79.

Ślusarczyk, B. (2018). Industry 4.0 - Are we ready? Polish Journal of Management Studies, 17(1), 232-248. doi: 10.17512/pjms.2018.17.1.19

Taulli, T. (2019). RPA (Robotic Process Automation): What's In Store For 2020? Forbes. Retrieved from https://www.forbes.com/sites/tomtaulli/2019/12/13/ rpa-robotic-process-automation--whats-in-storefor-2020/\#4fd8a12171de

Tian, Z. (2018). RPA + data analytics = an unprecedented force for digital transformation, PwC. Retrieved from https://www.pwc.ch/en/insights/digital/rpadata-analytics-an-unprecedented-force-for-digitaltransformation.html

Tornbohm, C., \& Dunie, R. (2017). Market Guide for Robotic Process Automation Software, Gartner, Stamford. Retrieved from https:/www.gartner.com/en/ documents/3835771/market-guide-for-robotic-process-automation-software

van der Aalst, W. M. P., Bichler, M., \& Heinzl, M. (2018). Robotic Process Automation. Business \& Information System Engineering, 60(4), 269-272. doi: https://doi. org/10.1007/s12599-018-0542-4

Vedder, R., \& Guynes, C. S. (2016). The Challenge Of Botsourcing. The Review of Business Information Systems, 20(1), 1-4. doi: 10.19030/rbis.v20i1.9677

Willcocks, L., Lacity, M., \& Craig, A. (2017). Robotic process automation: strategic transformation lever for global business services? Journal of Information Technology, 7(1), 17-28. doi: 10.1057/s41266-016-0016-9

Winkowska, J., Szpilko, D., \& Pejić, S. (2019). Smart city concept in the light of the literature review. Engineering Management in Production and Services, 11(2), 70-86. doi:10.2478/emj-2019-0012 